\title{
Impact of geometry of the powered roof support section on the rock mass
}

\author{
Dawid Szurgacz ${ }^{1, *}$ \\ ${ }^{1}$ Polska Grupa Górnicza S.A., KWK ROW ruch Chwałowice, 4 Przewozowa St., 44-206 Rybnik, Poland
}

\begin{abstract}
The required functions of the powered roof support, the functions it must fulfil and the mechanical elements cause that the support practically continuously works with the rock mass. This applies to the canopy, the floor base and the shield support. Due to the different susceptibility and strength of the rocks, the roof support may lose its stability. This condition results in an uneven section load and difficulties with moving forward the support in the underground excavation. This, in turn, can lead to disturbances in the operation of the entire longwall system. In order to avoid this situation, it is necessary to conduct geometry tests, e.g. section tests for a dedicated testing station using innovative measuring inclinometers. They indicate the importance of proper geometry for proper and correct operation of the support section. The research was carried out with the use of a new methodology designed to test the geometry of powered roof supports. The solutions were developed by the author of the article.
\end{abstract}

\section{Introduction}

Mining roof support is a basic protection of underground mining excavations [1-3]. It covers the roof support of corridor workings [4-6] and the roof support of longwall workings. A powered roof support is a machine that forms the basis of a powered longwall system. Its role is to secure a longwall working in which the mining process is carried out. Its task is to protect the working space in case of deformation of the rock mass. The basic assumption of the entire system is to create resistance to the rock mass pressing the mining area. Each section of the powered roof support must also be able to move forward as the coal seam is being mined. In addition, the powered roof support sections cooperate with each other by means of so-called correction actuators. This in turn makes it possible to move them correctly in longwall workings with a large longitudinal slope. The roof support is subjected to static and dynamic loads. Static loads are the result of slow movements and deformations of the rock mass. Dynamic loads are the result of rapid changes in the state of balance in the rock mass $[7,8]$.

In a longwall complex, a unit of powered roof support consists of sections that are connected to a longwall conveyor by means of a sliding system. Due to the initial position of the roof support, in relation to the conveyor, it is the basis for moving the entire complex as the operation progresses. During this process, the support performs specific tasks supporting a new roof of the excavation (after driving the longwall coal-cutter). Moving the roof support to the plane of the wall ends in its expansion. Then, under the shifted support, a longwall conveyor moves along behind the longwall coal-cutter located in a certain distance. Therefore, it can be assumed that the support works in a closed production cycle. The phases of its operation include withdrawing, moving in the excavation and spreading between the roof and the floor. In each of these phases, it is fundamental to maintain proper roof support stability.

It should also be emphasized that the powered roof support is the most expensive component of the whole powered longwall system. Therefore, its sections are used in mines for a long time and consequently, a great number of systems used underground are outdated. In many cases the constructions are equipped with old hydraulic systems. Nonetheless, such systems must also meet high requirements for stability and safety in a longwall work.

The author attempted to determine the impact of geometry of the powered roof support on the rock mass. For this purpose, stationary tests of the powered roof support were carried out.

Obtained results, according to the author, should be applied to develop a new section design that will provide even better working conditions in difficult mining and geological conditions. At the same time, it should improve work safety and work efficiency of the entire powered complex.

\section{Analysis of cooperation between roof support and rock mass}

The rocks surrounding the mining area are part of the rock mass in which the mining operations are carried out. Elements of the rock mass, which the support

\footnotetext{
* Corresponding author: dawidszurgacz@vp.pl
} 
cooperates with, are the floor and the caving area (Fig. $1)$.

The structure of the longwall roof support takes over loads in the form of roof rocks and transfers it to the floor impacting on the support. Therefore, the cooperation of the roof support with the rock mass depends both on the construction of the roof support and on the mechanical properties of the rock mass in which the excavation is made. Very important are also the parameters of the caving or rock rubble created in the selected space behind the roof support. This also affects the ventilation parameters of the entire area [9, 10]. For this reason, the structural features of the support should be adjusted both to the quality of floor and floor rocks. The interaction between these centres greatly impacts on the nature of the load and its effects, as well as the actual mining process. The diagram of cooperation between the roof support and the rock mass presented in Figure 1 reflects the essence of this interaction. Based on this model, tests of the roof support section were carried out.

The tests were performed on the ZRP-15/35-POz support section. It is a chock and shield support equipped with two hydraulic legs. The legs work in a position deviating from the direction of the load. This causes a complex load condition of the section construction, which is a particularly unfavourable for work in the low altitude range. The inclination of the legs causes that the canopy is supported in a place closer to the exploited seam, which supports the roof in the front part of the excavation, however, the rear part of the canopy, located in some distance from the seam, is not supported by the leg.

A schematic diagram of the construction of roof support section is shown in Figure 2. Figure 3 presents constructed section.

The support of the canopy located between the canopy and the shield support has a significant influence on the geometry of the support. The most common cause of poor cooperation between the powered roof support sections and the rock mass is the difficulty in obtaining the correct geometry. The basis of this geometry is setting of the canopy, so that when it comes into contact with the roof its upper surface is parallel to the ceiling surface.

The analyzed powered roof support type ZRP-15/35$\mathrm{POz}$ is a supporting and shielding structure, equipped with two hydraulic legs and a lemniscate guiding mechanism for the canopy. It is intended for supporting the roof in horizontal excavations and longitudinal and transversely longitudinal excavations. The section can cooperate with basic compact, medium compact and brittle roofs. The roof support can be used in hazardous and non-hazardous deposits. The support as a component of the longwall systems is adapted to cooperate with various conveyors and a longwall coal-cutter. The section is adapted to work in walls with a height of more than $2.4 \mathrm{~m}$, where the canopy is equipped with face shields.

The type of loads carried by the roof support varies. They result from free rock mass movement (static load) or violent movement of the rock mass (dynamic load). The type of load and the output setting of the section has a huge impact on its response, i.e. its reaction to these loads.

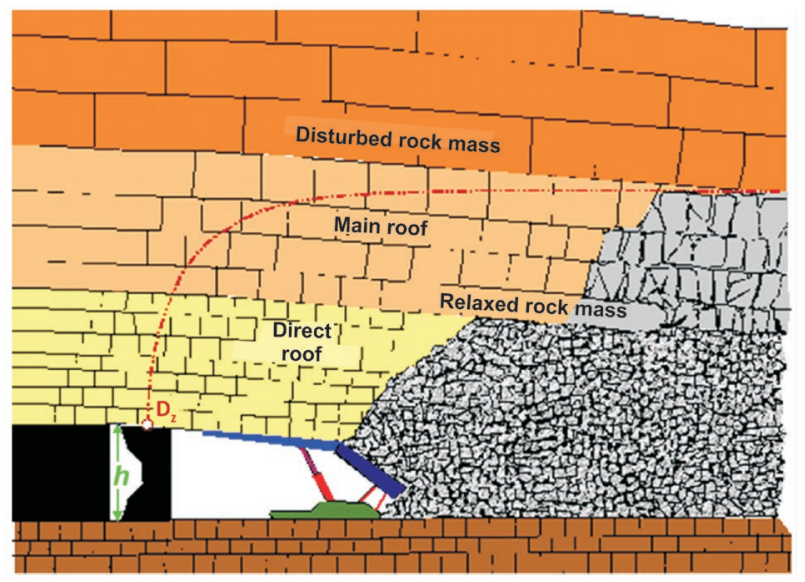

Fig. 1. Scheme cooperation of the roof support and rock mass, $h$ - height, $D_{2}$ - main roof sagging zone [7].

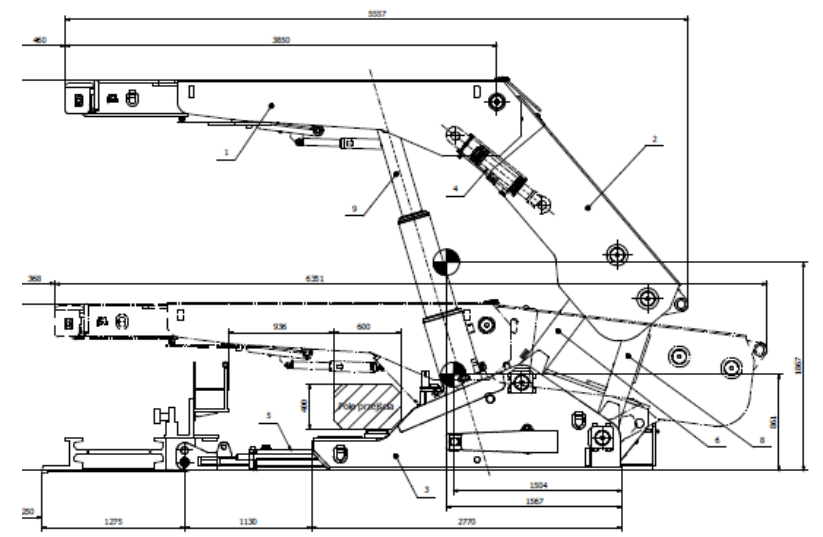

Fig. 2. Roof support section.

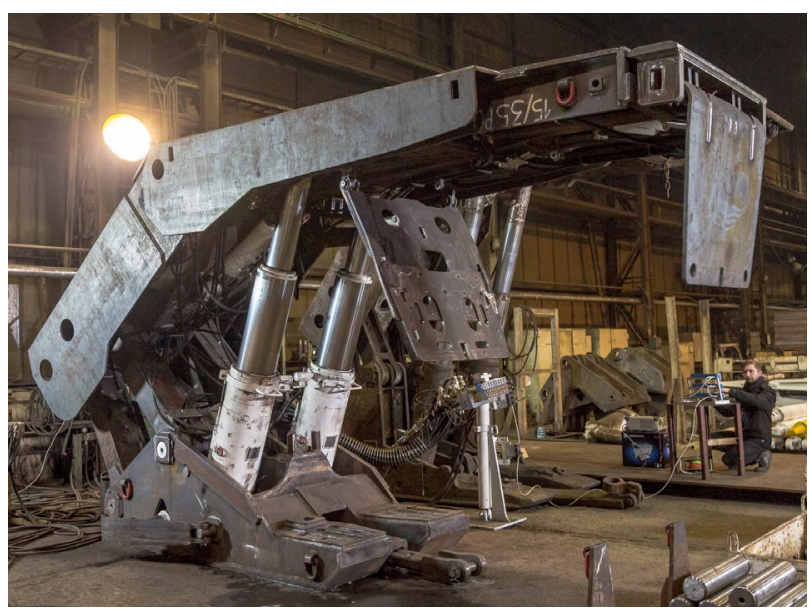

Fig. 3. A prototype ZRP-15/35-POz section.

\section{Section geometry analysis}

The conditions of tests assumed a flat model of the section, taking into account all elements of the section's kinematic chain. This model was analysed to determine 
its geometrical and kinetostatic features. The analysis of geometrical features included a model of a prototype section of a powered roof support, type ZRP-15/35-POz used to the full extent. During the research, it is necessary to set a number of requirements, among others: determining the correct scope of the section work, how the roof will be exposed, the determination of resistance parameters and the lemniscate curve. In terms of structural analysis, the roof support section can be treated as a flat mechanism with 2 degrees of freedom. This mechanism consists of eight rigid units connected by nine sliding pairs.

The kinematic chain of the studied section has been analysed mainly in terms of kinematics. Model's data was provided in the form of dimensions of individual structural elements: canopy, floor base, front and rear connections and shield supports. In addition to the working range, a geometric calculation was taken into account, which determines what intermediate heights of the work range will be made. The calculation process began with determining and checking the geometry of the kinematic chain. It can be automatically interrupted when a solution is not found, or the obtained results exceed certain limit values. In this case, adjustments should be made, and the calculation should be repeated. The tests were carried out based on the measurement of

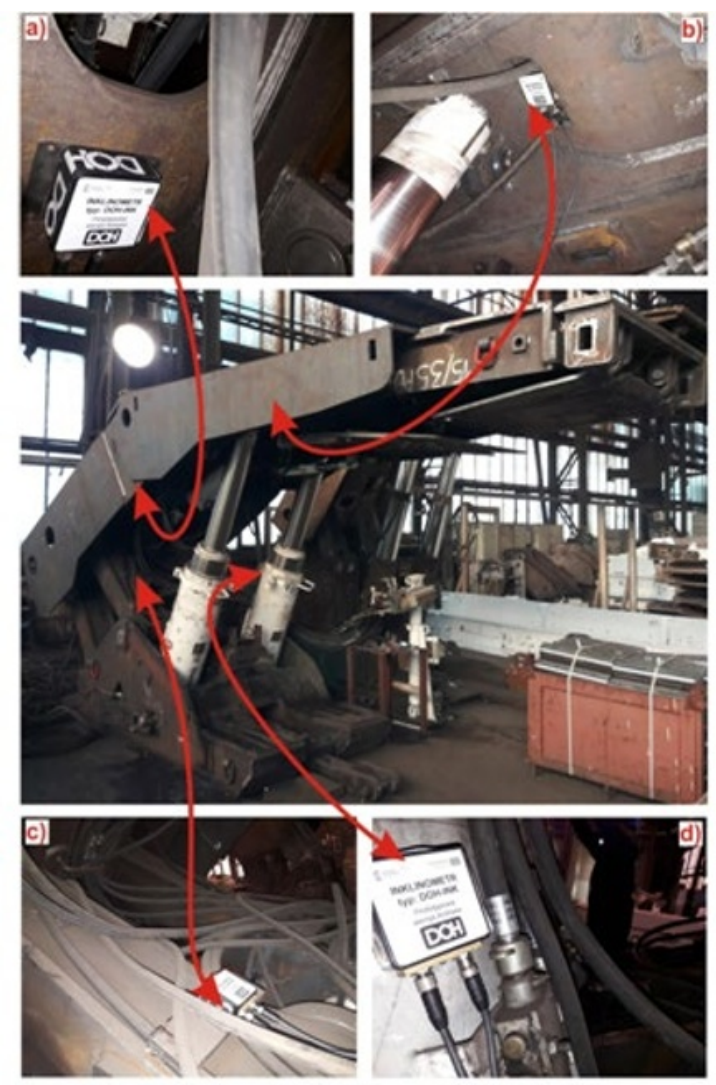

Fig. 4. Arrangement of DOH-INK prototype inclinometers on the ZRP-15/35-POz section model. the slope of the section in space with the required accuracy, the reading of which is carried out by means of digital transmission of results. Prototype inclinometer sensors were placed respectively in the construction of the section, as shown in Figure 4.

Geometric calculations were carried out for 3 cases: horizontal canopy and leaning at a positive (upward) and negative (downward) angle. In addition, the systems allow to choose the option of calculating with or without taking into account the actuator's minimum and maximum length of the canopy support. The option that includes the defined support range allows to get the full geometry data of the system with the minimum angles that can be reached by the canopy while operating within the defined range. In turn, the analysis of results obtained without considering the support helps to choose the appropriate range.

Obtained results of geometric calculations are available in the form of numerical data (point coordinates, angles: legs, connectors, bar, length: legs, supports, etc.). All are determined depending on the height of the section. A scheme of the flat model for different cases is shown in Figures 5 and 6 . The obtained test results are listed in Tables 1 and 2. The results were used to determine the shape of the area where the roof is not shielded, which is also visible in Figures 5 and 6 .

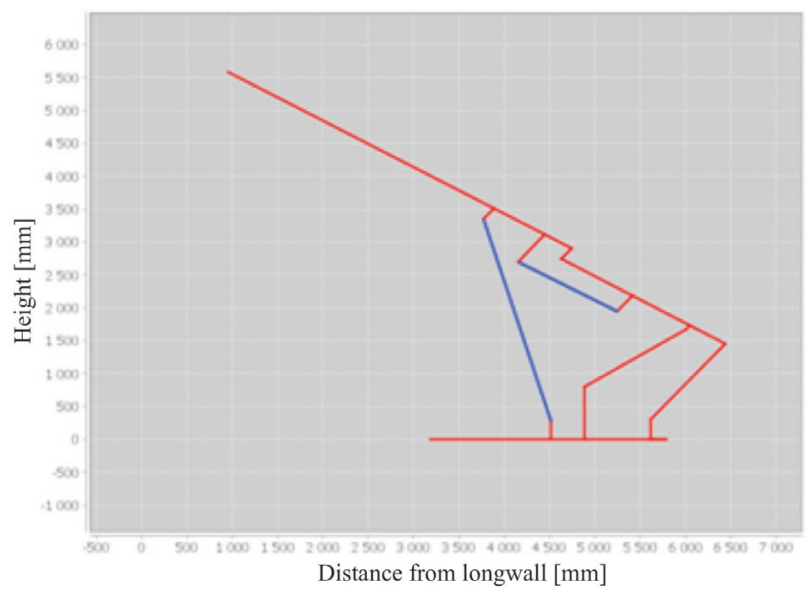

Fig. 5a. Geometric analysis of the angle of inclination, where the angle for the canopy is $\alpha=35.36^{\circ}$.

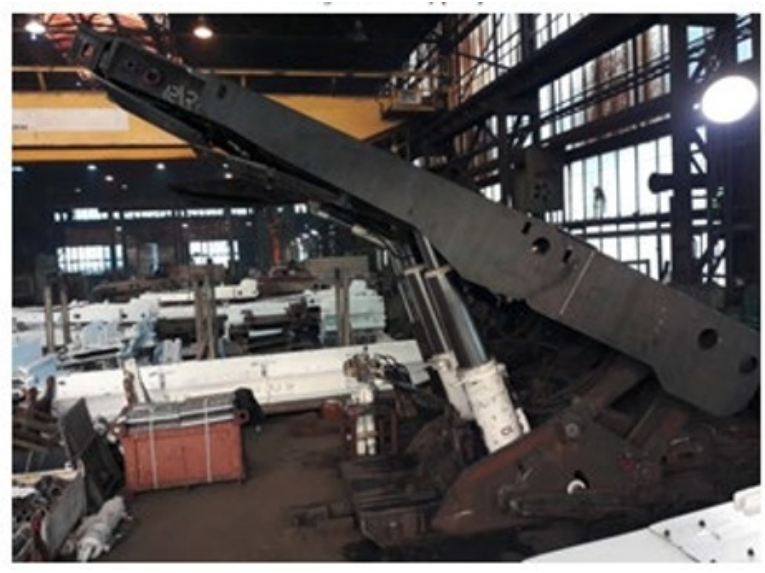

Fig. 5b. The shield support $\alpha=35.37^{\circ}$ for the canopy. 
Table 1. The results of the calculation of the positive angle for the canopy.

\begin{tabular}{|c|c|c|c|c|c|c|}
\hline $\begin{array}{l}\text { Leg's height } \\
\text { [mm] }\end{array}$ & $\begin{array}{c}\text { Uncovered area } \\
{[\mathrm{mm}]}\end{array}$ & Angle $x 1\left[^{\circ}\right]$ & Angle $x 2\left[^{\circ}\right]$ & Angle $x 3\left[^{0}\right]$ & Angle $x 4\left[^{\circ}\right]$ & Angle $x 5\left[^{\circ}\right]$ \\
\hline 1,423 & -41.12 & 8.07 & 27.68 & 84.94 & 133.61 & 5.03 \\
\hline 1,494 & -19.77 & 9.07 & 28.26 & 83.37 & 130.77 & 6.61 \\
\hline 1,567 & 5.4 & 10.14 & 28.93 & 81.8 & 128.15 & 8.17 \\
\hline 1,643 & 34.18 & 11.26 & 29.68 & 80.26 & 125.72 & 9.72 \\
\hline 1,722 & 66.37 & 12.45 & 30.52 & 78.72 & 123.48 & 11.26 \\
\hline 1,803 & 101.77 & 13.69 & 31.43 & 77.19 & 121.41 & 12.78 \\
\hline 1,886 & 140.2 & 15.0 & 32.44 & 75.67 & 119.49 & 14.3 \\
\hline 1,971 & 181.48 & 16.36 & 33.53 & 74.16 & 117.71 & 15.81 \\
\hline 2,057 & 225.46 & 17.79 & 34.7 & 72.66 & 116.07 & 17.31 \\
\hline 2,145 & 271.99 & 19.27 & 35.96 & 71.17 & 114.55 & 18.8 \\
\hline 2,235 & 320.99 & 20.8 & 37.31 & 69.68 & 113.14 & 20.29 \\
\hline 2,325 & 372.39 & 22.39 & 38.73 & 68.19 & 111.84 & 21.78 \\
\hline 2,417 & 426.14 & 24.03 & 40.23 & 66.71 & 110.63 & 23.26 \\
\hline 2,509 & 482.26 & 25.71 & 41.82 & 65.22 & 109.51 & 24.75 \\
\hline 2,602 & 540.81 & 27.44 & 43.47 & 63.73 & 108.46 & 26.24 \\
\hline 2,696 & 601.87 & 29.21 & 45.2 & 62.24 & 107.49 & 27.74 \\
\hline 2,789 & 665.56 & 31.02 & 46.99 & 60.73 & 106.58 & 29.24 \\
\hline 2,883 & 732.03 & 32.85 & 48.84 & 59.22 & 105.73 & 30.76 \\
\hline 2,976 & 801.42 & 34.69 & 50.74 & 57.69 & 104.93 & 32.28 \\
\hline 3,068 & 873.84 & 36.55 & 52.67 & 56.16 & 104.17 & 33.82 \\
\hline 3,158 & 949.27 & 38.39 & 54.64 & 54.62 & 103.45 & 35.36 \\
\hline
\end{tabular}

Table 2. Negative angle calculation results for the canopy.

\begin{tabular}{|c|c|c|c|c|c|c|}
\hline $\begin{array}{c}\text { Leg's height } \\
\text { [mm] }\end{array}$ & $\begin{array}{c}\text { Uncovered area } \\
{[\mathrm{mm}]}\end{array}$ & Angle $x 1\left[^{\circ}\right]$ & Angle $x 2\left[^{\circ}\right]$ & Angle $x 3\left[^{\circ}\right]$ & Angle $x 4\left[^{0}\right]$ & Angle $x 5\left[^{\circ}\right]$ \\
\hline 1,423 & 774.54 & 24.02 & 40.23 & 66.72 & 121.06 & -36.67 \\
\hline 1,494 & 725.87 & 25.29 & 41.41 & 65.59 & 119.89 & -35.55 \\
\hline 1,567 & 676.95 & 26.62 & 42.68 & 64.44 & 118.79 & -34.4 \\
\hline 1,643 & 627.98 & 28.01 & 44.02 & 63.25 & 117.76 & -33.21 \\
\hline 1,722 & 579.12 & 29.46 & 45.44 & 62.03 & 116.8 & -31.98 \\
\hline 1,803 & 530.55 & 30.96 & 46.93 & 60.77 & 115.8 & -30.73 \\
\hline 1,886 & 482.43 & 32.52 & 48.5 & 59.49 & 115.06 & -29.44 \\
\hline 1,971 & 434.96 & 34.12 & 50.15 & 58.16 & 114.27 & -28.12 \\
\hline 2,057 & 388.35 & 35.77 & 51.86 & 56.8 & 113.53 & -26.76 \\
\hline 2,145 & 342.85 & 37.46 & 53.64 & 55.4 & 112.83 & -25.36 \\
\hline 2,235 & 298.75 & 39.18 & 55.48 & 53.96 & 112.16 & -23.92 \\
\hline 2,325 & 256.41 & 40.92 & 57.39 & 52.47 & 111.52 & -22.42 \\
\hline 2,417 & 216.25 & 42.7 & 59.35 & 50.93 & 110.9 & -20.88 \\
\hline 2,509 & 178.8 & 44.48 & 61.37 & 49.33 & 110.29 & -19.28 \\
\hline 2,602 & 144.69 & 46.28 & 63.44 & 47.67 & 109.68 & -17.62 \\
\hline 2,696 & 114.69 & 48.07 & 65.44 & 45.93 & 109.06 & -15.89 \\
\hline 2,789 & 89.72 & 49.85 & 67.69 & 44.13 & 108.43 & -14.08 \\
\hline 2,883 & 70.85 & 51.6 & 69.85 & 42.24 & 107.77 & -12.19 \\
\hline 2,976 & 59.34 & 53.31 & 72.03 & 40.26 & 107.07 & -10.21 \\
\hline 3,068 & 56.59 & 54.95 & 74.2 & 38.19 & 106.33 & -8.14 \\
\hline 3,158 & 64.06 & 56.52 & 76.35 & 36.03 & 105.53 & -5.98 \\
\hline
\end{tabular}




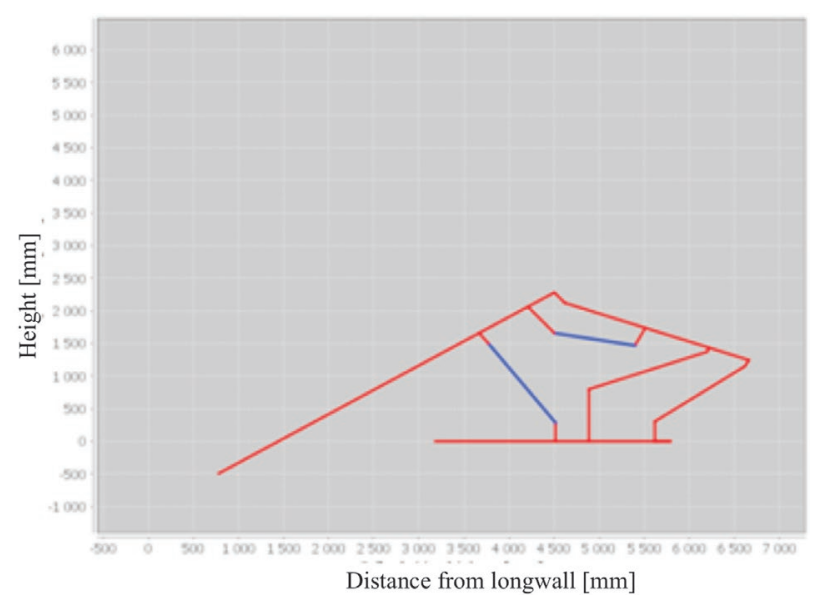

Fig. 6a. Geometric analysis of the angle of inclination, where the angle for the canopy is $\alpha=-36.67^{\circ}$.

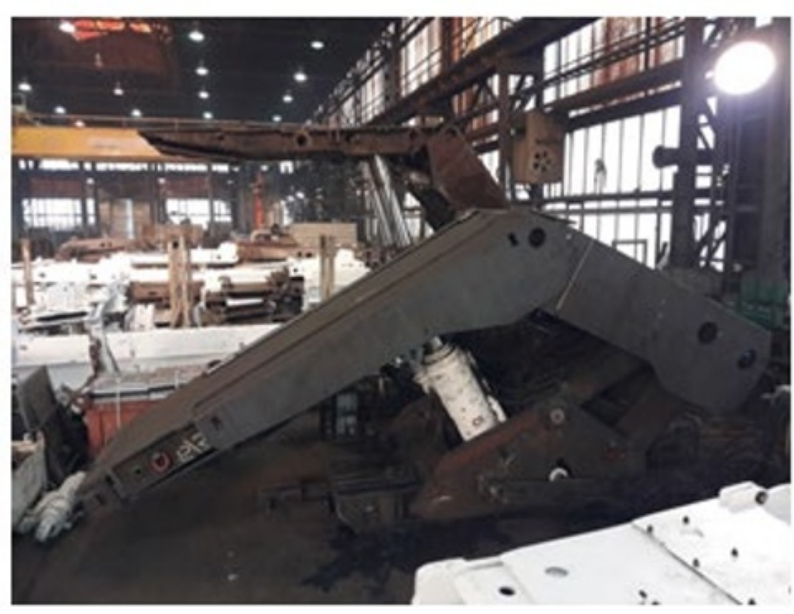

Fig. 6b. The shield support, $\alpha=23.27^{\circ}$ for the canopy.

\section{Conclusion}

The conducted research analysis was aimed at determining the actual geometry of the section depending on the setting of its elements. The measuring system developed by the author consisting of inclinometer sensors and appropriate software was used for the research. The measurement-recording system used in the tests has passed the positive practical tests before. Ultimately, it will be used in the newly emerging innovative electro-hydraulic control system for the powered longwall system. It will also be used to visualize the spatial position of the roof support section during its operation. The system is an innovative solution and currently is subject to a series of tests.

The tests carried out and the results obtained clearly indicate that the roof support's operating parameters depend on its geometry. This, in turn, impacts on the correctness of its cooperation with the rock mass. In this respect, it is the most important to ensure that the canopy is mounted parallel in relation to the sidewall of the excavation. The tests are the first stage designed to study the sections in underground conditions. For this reason, the positive verification of the developed methodology as well as the measurement and recording system are promising.

It is assumed that this methodology together with the measurement system will be used also underground. This should be used to build a wireless control system with the entire powered roof.

The conducted research also indicate that the results obtained from the calculations of the canopy deflection in a positive or negative angle coincide with the actual values. On this basis, it can be concluded that the developed model accurately reflects the actual state and can be used for further research. Also, the prototype measuring and recording system has fulfilled its function. In particular, this applies to innovative inclinometers that correctly determined the location of the sections during operation. The wider use of the obtained results is also connected with the possibility of their use in the systems already developed and applied for the study of the affective use of mining machines [11-14].

Obtained results should, therefore, be a new important source of knowledge in the field of powered support systems and improve their efficiency and safety.

The work was carried out within the project 'Innovative electro-hydraulic control system for powered roof support' No. POIR.01.01.01-00-1129/15. The Operational Programme Smart Growth 2014 - 2020 carried out by the National Centre for Research and Development.

\section{References}

1. M. Blaschuk, A. Dronov, A. Koperchuk, R. Chernukhin, V. Litvienko, E3S Web Conf., 15 (2017)

2. G. Buyalich, K. Buyalich, M Byakov, E3S Web Conf., 21 (2017)

3. S. V. Klishin, V.I. Klishin, G. Yu. Opruk, J. Min. S. 49:6, 932 (2013)

4. J. Brodny, Arch. Min. S. 55, 4, 733-746 (2010)

5. J. Brodny, Arch. Min. S. 56, 2, 303-318 (2011)

6. J. Brodny, Arch. Min. S. 57, 1, 209-227 (2012)

7. S. Prusek, S. Rajwa, A. Wrana, A. Krzemień, Int. J. Min. Rec. E. 31:8 (2017)

8. D. Szurgacz, E3S Web Conf., 29 (2017)

9. M. Tutak, J. Brodny, E3S Web Conf., 29 (2018)

10. M. Tutak, J. Brodny, IOP Conf. Earth and Env. S. 95 (2017)

11. J. Brodny, M. Tutak, M. Michalak, BDAS, 441-452 (2017)

12. J. Brodny, M. Tutak, M. Michalak, BDAS. 453-465 (2017)

13. J. Brodny, M. Tutak, E3S Web Conf., 29 (2018)

14. J. Brodny, S. Alszer, J. Krystek, M. Tutak, Arch. of Cont. S. 27(LXIII), 2, 197-209 (2017) 